\title{
PSYCHOANALYTIC TECHNOLOGIES APPLICATION IN LEGAL EDUCATION
}

\author{
Julia N. Kuznetsova \\ Kazan Federal University, Law department, (Russia). \\ E-mail: knopjul@mail.ru ORCID: https:// orcid.org/0000-0001-7808-6543
}

Arthur G. Ibragimov

Kazan Federal University, Law department, (Russia).

E-mail: arthur.ibragimov@yandex.ru ORCID: https://orcid.org/0000-0002-4282-7482

\section{Citación sugerida:}

Kuznetsova, J. N., y Ibagimov, A. G. (2020). Psychoanalytic technologies application in legal education. 3C TIC.

Cuadernos de desarrollo aplicados a las TIC, 9(1), 87-97. http://doi.org/10.17993/3ctic.2020.91.87-97 


\section{ABSTRACT}

In this work the new system of psychology and pedagogical knowledge, ideas, principles are considered. The psychoanalytic method is considered as the tool for the solution of legal education problems. The modern psychoanalytic ideas reflected in the works of Buettner (1991), Singer (1970), Helbig (1978), Datler (1985), etc. are analyzed. Justification is given that the legal education and legal education containing and applying psychoanalytic technologies promotes elimination of the symptoms indicating emergence of the mental overloads peculiar to teenage age owing to psychophysiological features and as a result of imposing by adults of the authoritative knowledge. Introduction of psychoanalysis to number of educational measures for forming sense of justice, it is necessary to begin as soon as possible that will provide the prevention of big nervous shocks in connection with understanding of in legal society and different elimination of violations in mental development of the student and his activity. The possibility of introduction of psychoanalytic technologies in relation to legal training is studied. Use of psychoanalytic technologies, is considered in the context of traditional legal pedagogics where the special part is assigned to psychology, considering the person in unity of psychosocial development. Only in such interrelation it is possible to count on the complete and objective solution of the psychological and pedagogiclegal problems facing us.

\section{KEYWORDS}

Pedagogical Technologies, Psychoanalysis, Legal Education, Legal Education, Psychoanalytic Pedagogics. 


\section{INTRODUCTION}

Today, when there is an active introduction of various educational technologies directed to legal training and education of the personality included in the activity in the political, economic, social, cultural, educational sphere of interaction, insufficiently developed there is a problem of the choice of the most effective modern technologies in education. Today in educational space, legal education is considered as process of forming respect for the law, the statement in consciousness of the identity of importance of the law as necessary social value; development in the identity of the necessary characterologic qualities promoting development of irreconcilability to violation of the law. The educational and training measures will create consciousness of the personality and over time and legal culture of society in general.

The accepted Concept of spiritual and moral development and education of the identity of the citizen of Russia assumes to look in a new way at the ideas of psychology and pedagogical heritage of last years and to their judgment according to current trends of development of modern society. And introduction of innovations in Russian education, assumes use of the personal focused pedagogical technologies in education considering psychological knowledge of an etiology of development of the personality.

The psychoanalytic theory of education corresponds to current trends of development of education and education of younger generation as the central place in it is taken by humanistic priorities. Exactly considering dynamics of development of mental processes of the personality we can speak about humanity in education. The psychoanalytic theory pays the main attention to the identity of the student, concentrates on features of her development, and it also assumes individual approach in the course of training and education (Horns, 2010).

\section{METHODS}

Analysis, synthesis, modeling, abstraction, transfer, analogy, generalization, dialectic method of knowledge and system approach. 


\section{RESULTS AND DISCUSSION}

Psychoanalytic theories already in the first half of the 20th century began to exert impact on development of a pedagogical thought; to volume the edition of the Magazine of Psychoanalytic Pedagogics magazine demonstrates what defined emergence of the term psychoanalytic pedagogics. Psychoanalysts offered the idea of "education of tutors" before selfknowledge. Followers of the psychoanalytic ideas of education considered that psychoanalysis plays an important role in the sphere of individual prevention of asocial behavior, and in pedagogics is positive educational system (Rank, 2009).

However in the pedagogical theory and practice of the organization of teaching and educational process within legal education the principles of modern psychoanalysis which can be applied for forming sense of justice of the personality, and correction and prevention of illegal behavior are almost not involved.

Ensuring harmonious state of mind of the personality requires, at least, two factors it is moral values and public norms of modern society and how the personality perceives them, on the one hand; with another, its personal relations with the immediate environment. Can be the reason of development of asocial behavior when on the basis of these two factors rigid borders in structure of mentality, otherwise, painful experiences are formed, are forced out to the area unconscious where remain demanded and urgent throughout all life, forming a certain rigid scheme according to which all further mental life of the personality is under construction. The personality gets various character accentuations which find the expression in various forms of deviant behavior. Mental health assumes constant conscious control over own opportunities, control to perceive reality really, ability to interact adequately with people around, without becoming the hostage of the fears introduced from the childhood.

To expand possibilities of teachers and psychologists in the sphere of forming sense of justice of students, the psychoanalytic method which initially was considered by the classic of psychoanalysis 3 allows. Freud as the tool for the solution of problems of training and education. 
Buettner, Singer, Helbig, Datler's works as representatives of modern psychoanalytic pedagogics can represent a certain resource for the Russian teachers in work with aggressive children and teenagers (Buettner, 1991; Figdor, 1999; Figdor, 1982; Helbig, 1978; Singer, 1970; Kuznetsova \& Ibragimov, 2016).

The Austrian psychoanalyst and the psychotherapist Helmut Figdor revived the ideas of classical psychoanalytic pedagogics and adapted them to our time. Figdor, being the expert in affairs of minors at the Vienna court and dealing with problems of resocialization of the teenagers who made offenses declared need of introduction of psychoanalysis in educational process (Helbig, 1978).

After Freud, Singer and Helbig attached huge significance to the personal relations between teachers and students. Zinger suggests not to demand from students of work, and to work with them together. In psychoanalytic terminology it assumes to give the chance to students to try on itself a working position by method of identification of with the teacher, but not by execution of abstract requirements "super I" (Singer, 1970; Kuznetsova \& Ibragimov, 2016; Teres, Ribeiro, \& Cardoso, 2018; Marandi et al, 2018).

Bernfeld, being guided by achievements of psychoanalytic science of Freud and his pupils, claimed that it is necessary to develop abilities of teachers to build up the relationship with pupils, relying on psychology and pedagogical knowledge. Bernfeld fairly emphasized that the negative phenomenon of modern society are people who for one reason or another had no significant adults in whom they could trust. And in the investigation absence supports from the adult were given in group outcast, neglected society of people and could not show individual bents, develop inclinations, be implemented as persons, to become useful members of society. Bernfeld's work with children with deviant forms of behavior was based on the analysis of children's psychology, pedagogical experience and psychoanalytic penetration into sincere experiences of pupils. Educational actions went for reorientation of deviant lifestyle, and the feeling of insufficiency, inferiority, complexes which motivated children on the solution of the problems with primitive demonstration of aggression were compensated by socially acceptable forms of behavior (Obraztsova, 2006; Datler, 1985). 


\section{CONCLUSION}

Proceeding from Freud's statements, the mentality of the person consists of three components (his) Ides, the Ego (I) and Super the Ego (Super I). Ides is completely unconscious, cope with the principle of pleasure and contains congenital unconscious instincts. Respectively if internal motives of Ides are will receive a free exit, then the personality will act within asocial behavior. SuperEgo is a carrier of moral standards and if internal motives of the personality are forced out by SuperEgo, then persons will be peculiar various neurotic manifestations that eventually will lead to development of various forms of deviant behavior. The ego follows the principle of reality, its function at the same time adaptation to influences from Ides and to requirements of surrounding reality and if they are sublimated in socially useful activity, the personality herself will be able to selfactualize without any tension's society. For elimination of the first two possible options of development of the personality it is necessary or to lower the public requirements imposed to the individual and by that to weaken replacement process, or to determine possibilities of human consciousness in fight against instincts and by means of rational control over the actions to increase ability of the individual to switching of energy to socially acceptable objects and the purposes (Bernfeld, 1970).

If not in our direct power quite lower requirements of society imposed on the individual, then we can, work with individual and collective consciousness in the field of development and forming the right conscious personality.

The main goal of legal education, proceeding from the theory of psychoanalysis, is in understanding the nature of unconscious motives of behavior of the personality, to open his egoistical requirements and motives, having redirected them on the way of sociocultural selfexpression, that is to carry out switching of inclinations by transfer of interest of the pupil on other objects without change of incentive motive. Thus one of the main educational objectives is switching of the child from thoughts in which the principle of pleasure (Ides), and connection it to the values and norms of life accepted in legal society prevails. 
Process of awareness of the requirements relates to awakening of such universal values as good, conscience, justice, responsibility, a debt, shame, etc. which become the main regulators of behavior of the personality. Thus, the field of consciousness of the personality is filled with valuable orientations, achieving thereby the objectives forming sense of justice of the personality. To reach it, it is necessary to create system of valuable orientations at the student, using possibilities of consciousness and sub consciousness.

The personality, being guided by own system of valuable orientations, is fixed in the choice of the acts and actions according to the offered social situation. The person does what he is (Kuznetsova, 2014).

Subconsciousness stirs up activity of the personality and forms readiness for mastering and performance of the social role according to precepts of law of society.

The legal education which is based on psychoanalytic knowledge promotes removal of the mental overloads arising at the student as a result of imposing by society in the person of parents, tutors, teachers, public norms and installations.

Introduction of psychoanalysis to number of educational measures for forming legal sense of justice, it is necessary to begin with the moment of hit of the child in system of the public relations that will provide the prevention of big nervous shocks in connection with understanding of in legal society and different elimination of violations in mental development of the personality and its activity.

With the help developed by Freud of the psychoanalytic equipment teachers must seize a gift to identify themselves with the student and to spontaneously understand the mental maintenance of its acts. As psychoanalysis facilitates to the teacher understanding of children's soul and the internal conflicts, typical for it, and introduction of psychoanalysis in pedagogics prepares the road to the relevant pedagogical activities. And as a result this understanding can be turned into practical actions. 
Interaction between psychoanalytic understanding and pedagogical actions fundamentals of psychoanalytic pedagogics.

The psychoanalytic model of legal education suggests not demanding from the rules and norms studying observance, and awareness of the importance of these norms in the course of activity. In psychoanalytic terminology it is called to give to students the chance to adopt social norms by identification of with these norms, but not by execution (abstract) requirements "super I".

The violations of these norms, only external manifestations demonstrating that the pupil does not submit to a compulsory educational system.

Legal education needs to be carried out according to the free choice of the personality, otherwise, it is impossible to bring up anything of that kind in the personality in what she does not see the valid and direct interest for her, pleasure or advantage.

The child is not really interested in improving the tool with which he is tormented; but make so that this tool served for his pleasure, and he will be engaged besides your diligence soon. Direct interest here great the engine, only which conducts truly and far (Russo, 1989).

\section{SUMMARY}

Thus, the discoveries made by psychoanalysts can directly and indirectly influence development of legal education of youth. And need of increase in level of professional competence of teachers through mastering by them by available methods of psychoanalytic pedagogics is obvious.

\section{ACKNOWLEDGEMENTS}

The work is performed according to the Russian Government Program of Competitive Growth of Kazan Federal University. 


\section{REFERENCES}

Bernfeld, S. (1970). Antiautoritare Education and Psychoanalysis. Third Frankfurt am Main, Lutz and Reinhard Wolfsmarz Verlag.

Buettner, K. (1991). To Live With Aggressive Children: The Lane with Him. Pedagogics.

Datler, W. (1985). Psychoanalytic Representatives of Counseling and Pedagogical Action. In Bittner, G., Ertle, C. (Eds.). Pedagogy and psychoanalysis.

Figdor, G. (1999). Psychoanalytic pedagogical consultation, Mos Freud 3. Introduction to psychoanalysis. Lectures. - SPb., Aleteya, t. II, 484.

Figdor, H. (1982). Conclusions on a pedagogical concept of "animation". Communications from the Institute of Science and Art, 34/4, Vienna.

Helbig, W. (1978). Schulische Proekte and on school activities with behavioral children. In Ertle, G., Schmid, V. (Hrsg.) The other lesson. Learning with children. Munchen.

Horns, N. T. (2010). Psychoanalysis and neopedagogics. Kazan pedagogical magazine, 3, 156.

Kuznetsova, Y. N. (2014). Values and their role in decision-making. The Kazan pedagogical magazine, 4, 156-161, issue id=1516331. http:/ / elibrary.ru/contents.asp

Kuznetsova, Y. N., \& Ibragimov, A. G. (2016). The correlation be-tween the psychological features of the personality with the structure of the values. Fournal of Organizational Culture, Communications and Conflict, 20, 59-63. https://www.questia.com/library/journal/1G1-500008919/the-correlationbetween-the-psychological-features 
Marandi, M., Shahi, M., Garalar, N. S., \& Khoyi, A. M. (2018). Losses resulting from the non-profit Consumer demand. Fournal of Social Sciences and Humanities Research, 6(03), 5-7. https://journals. researchub.org/index.php/JSSHR/article/viewFile/555/544

Obraztsova, L. V. (2006). Super activist's psychoanalytic pedagogics: Monograph. PGLU.

Rank, O. (2009). A trauma of the birth and its value for psychoanaly-sis. "Cogito-center".

Russo, J. J. (1989). Emil, or about education. In Pedagogical heritage. Pedagogics.

Singer, K. (1970). Lernhemmung, Psychoanalyse und Schulpadagogik. Munchen.

Tereso, A. P., Ribeiro, P. A., \& Cardoso, M. (2018). An Automated Framework for the Integration between EVM and Risk Management. Fournal of Information Systems Engineering E̊ Management, 3(1), 3. https://www.researchgate.net/publication/322669571_An_Automated_Framework_for_the_ Integration_between_EVM_and_Risk_Management 
